\title{
PREDICTION OF THE FLOW-INDUCED VIBRATION RESPONSE OF THE CHENDEROH DAM LEFT BANK SECTION
}

\author{
Mohamad Hazwan Mohd Ghazali ${ }^{1}$, Mohd Hafiz Zawawi², Nurul Husna Hassan², \\ Mohd Rashid Mohd Radzi ${ }^{2,3}$, Ahmad Zhafran Ahmad Mazlan'*, Mohamad Aizat \\ Abas $^{1}$ and Mohd Remy Rozainy Mohd Arif Zainol ${ }^{4}$ \\ ${ }^{1}$ School of Mechanical Engineering, Engineering Campus, Universiti Sains Malaysia, \\ Penang \\ ${ }^{2}$ Department of Civil Engineering, College of Engineering, Universiti Tenaga Nasional, \\ Selangor \\ ${ }^{3}$ TNB Generation Division, Tenaga Nasional Berhad, Kuala Lumpur \\ ${ }^{4}$ School of Civil Engineering, Engineering Campus, Universiti Sains Malaysia, Penang \\ *Email: zhafran@usm.my
}

\begin{abstract}
Flow-induced vibration is a common phenomenon that happened in any of dam structures during the operational condition. This includes the effect of water spilling from the upstream to the downstream of the dam due to high water volume at the upstream side. The release of water from the dam can be beneficial in generating the electricity source to the surrounding areas. However, in some cases, the spill of water can induced the significant vibration effects to the dam structure. In this study, the prediction of the flow-induced vibration response at the left bank section of the real scale Malaysian Chenderoh Dam model is simulated using the ANSYS software. The input force disturbances from the flow of the water at the left bank section during the normal water spilling condition is investigated. The results of frequency domain response and operational defection shapes (ODS) from the effect of flow-induced vibration are compared with the natural frequencies and mode shapes of the dam. From the results, the transient vibration responses due to the flow of water happened at the frequency of $13.3 \mathrm{~Hz}$ while the natural frequency of the left bank section occurred at $52.3 \mathrm{~Hz}$, which indicates that there is no resonance phenomenon for the normal case of water spilling at the left bank section of the dam structure. This result is useful for the dam operation section in order to avoid any disaster of the dam structure.
\end{abstract}

Keywords: Flow-induced vibration, water spilling, dam structure, operational deflection shapes, resonance.

\section{INTRODUCTION}

Vibrations induced by the fluid on the dam structure can lead to the catastrophic failure if its natural frequencies coincide with the shedding frequencies of the flow. Apart from that, this vibration can also reduce the performance of structure or equipment [1]. The value of the forces induced by the fluid depends on the pressure and velocity of the flow as well as the material properties of the actual structure [2]. Studies regarding the flowinduced vibration on various samples have been conducted over the years but only few of it involved the dam structures. Research on the sliding gate dam has been conducted by Ilgar et. al., [3] to study the dynamic behavior of the gate for different shape of 
valves. From this study, flat valve gate is found to have the highest possibility of damage to the dam wall. Another study has been conducted by Sanchez and Salazar that aims to determine pressure distribution and velocity profile of discharge flow for radial gates opening value of 2, 5, 10 and $14 \mathrm{~m}$, with 10 and 14 opening being the uncommon cases [4]. The flow rates for each opening are $12.07 \mathrm{~m}^{3} / \mathrm{s}, 11.85 \mathrm{~m}^{3} / \mathrm{s}, 11.85 \mathrm{~m}^{3} / \mathrm{s}$ and $11.47 \mathrm{~m}^{3} / \mathrm{s}$ respectively. From the simulation, there is a vortex formation for $10 \mathrm{~m}$ opening and also turbulence indicated at the discharge for $14 \mathrm{~m}$ opening. However, the results showed no sign of vibration due to the flow of water at the radial gate.

Generally, there are two types of water flow phenomenon in Chenderoh dam; water spilling and water surging. Water spilling occurs when all the gates are fully opened and maximum amount of water is released from upstream to downstream area. For the water surging, all the gates are suddenly closed during emergency cases. In this paper, the water spilling case is studied where the left bank section is modeled exactly as the original drawing of the Chenderoh dam. The FEM model used the properties of the real concrete materials and simulation study is performed using ANSYS transient structural and fluent workbenches and the results are compared with the modal and harmonic analyses.

\section{METHODOLOGY}

\section{Modelling of the Left Bank Section of the Dam Structure}

For the Chenderoh Dam, left bank section is the end part of the overall dam, where it connects with the bottom outlet section. This part is built half hollow and half solid. The three-dimensional (3D) model of the left bank section is constructed using SolidWorks software. Figure 1 shows the real and 3D model of the left bank section.

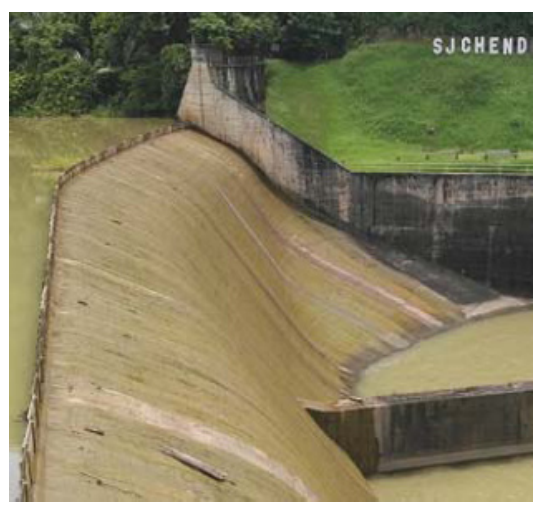

Figure 1: Picture of the real left bank section (left) and 3D model of left bank section (right)

\section{Boundary Condition of the Fluid and the Structure of the Dam}

For the left bank structure in the transient analysis, the boundary condition is where all the bottom faces are set as fixed support. The side faces that connected with the bottom outlet also been set as fixed support for this case as shown in Figure 2. 


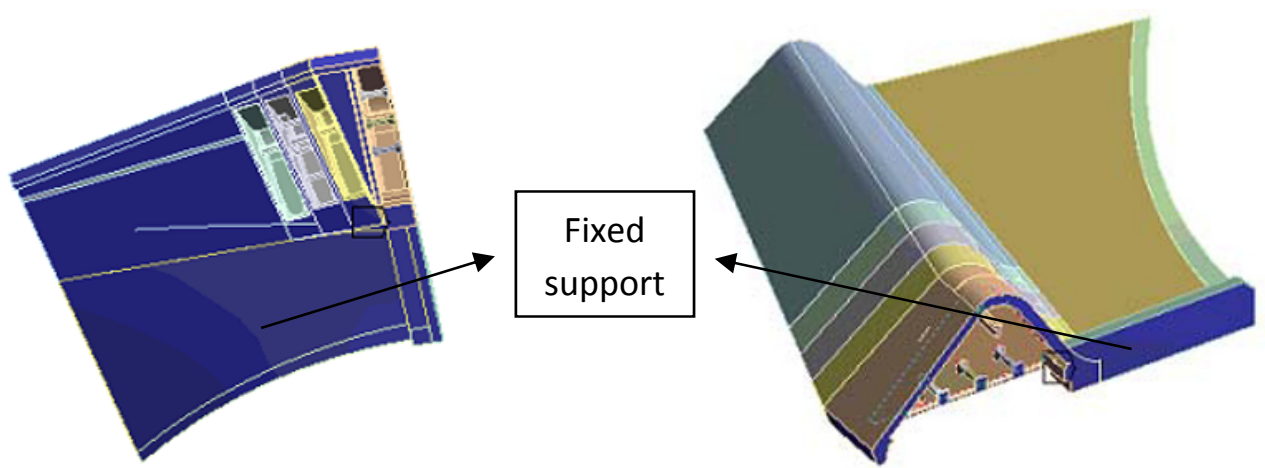

Figure 2: Boundary condition of structure at bottom (left) and side faces (right)

For the fluid, the types of boundary condition for inlet and outlet sections are velocity inlet and pressure outlet respectively. The velocity magnitude of water is set as $1 \mathrm{~m} / \mathrm{s}$. Figure 3 shows the inlet and outlet section of the left bank section.
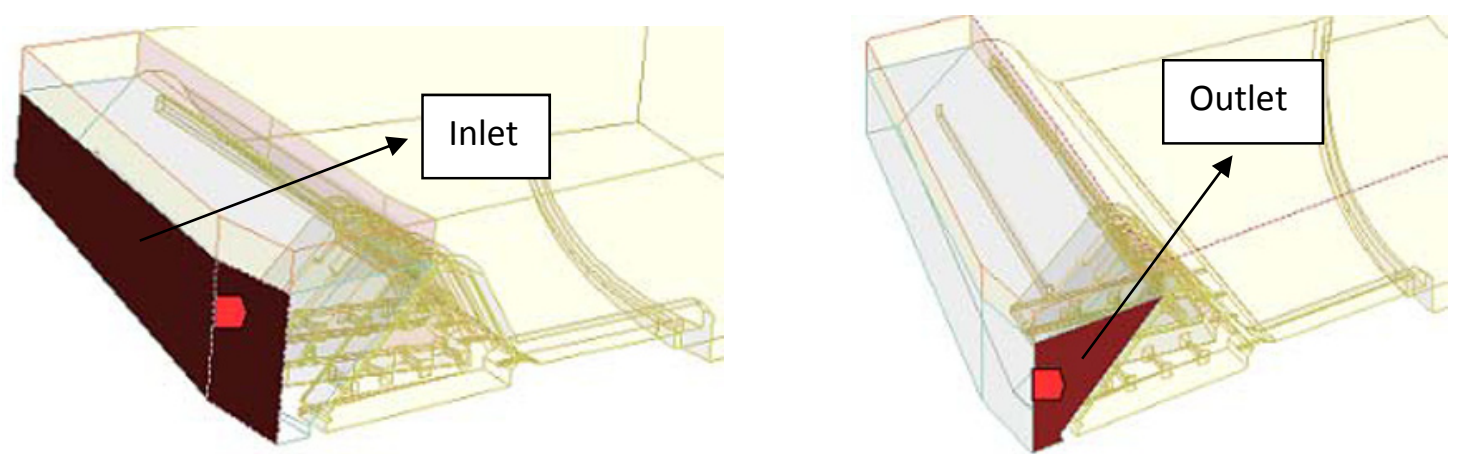

Figure 3: Inlet (left) and outlet (right) section for the left bank

\section{Two-way Fluid-structure Interaction (FSI) of the Left Bank Section}

Two-way FSI of the left bank section is made up of two systems analyses and one integrated system located in ANSYS software. The analysis systems are transient structural and fluid flow (fluent) whereas the integrated system is system coupling. All of this systems are linked together as shown in Figure 4.

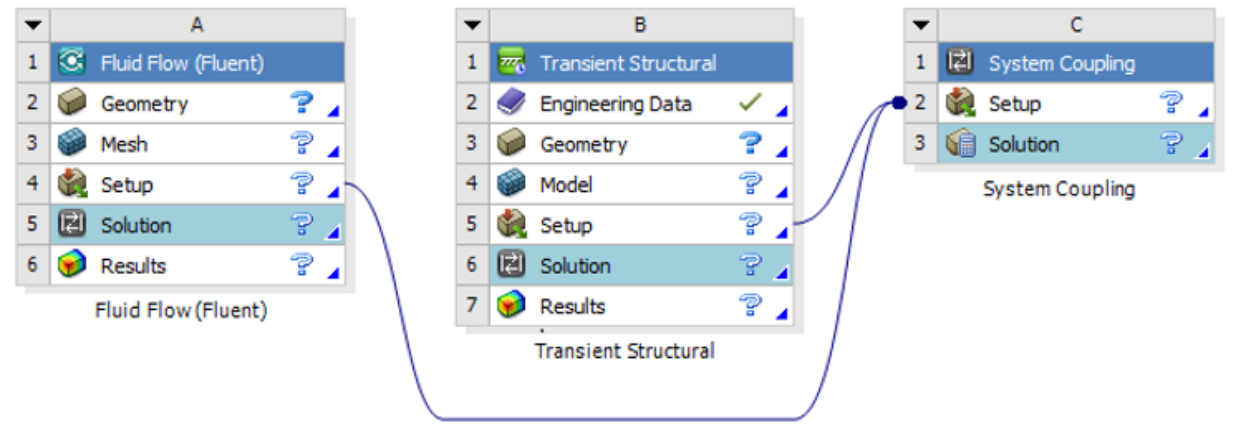

Figure 4: Linked setup between systems in two-way FSI 
For the transient structural system, the type of mesh used is hex dominant mesh. In the analysis of the left bank section, the step end time is set to 5 seconds and the step control is defined by substeps. The initial and minimum substep used is 1 and the maximum substep is 100. After setting-up the boundary condition as shown in Figure 2, the standard Earth gravity acceleration of $9.8 \mathrm{~m} / \mathrm{s}^{2}$ is applied at $-y$ direction. In the fluent system, an automatic mesh is used in order to reduce the simulation cost in terms of time and number of elements. A $2^{\text {nd }}$ order upwind is chosen for the solution method of turbulent kinetic energy and dissipation rate. 0.01 second is set as a time step size with maximum iteration of 200 times. In the system coupling (integrated system), the end time is set similar to transient structural system which is 5 seconds and the time step size used is 0.01 second, similar to fluent system.

\section{RESULTS AND DISCUSSION}

\section{ODS Results of the Left Bank Section}

Figure 5 shows the ODS of the left bank section with maximum displacement of $1.18 \mathrm{x}$ $10^{-3} \mathrm{~m}$ occurs at the upper section of the left bank. On the other hand, there is no significant effect on the apron caused by the water. It can also be observed in Figure 6, the ODS of left bank section in terms of time and frequency domain. From the frequency domain graph, the highest overall deflection occurs at an operating frequency of $13.3 \mathrm{~Hz}$ with maximum displacement value of $2.51 \times 10^{-3} \mathrm{~m}$.

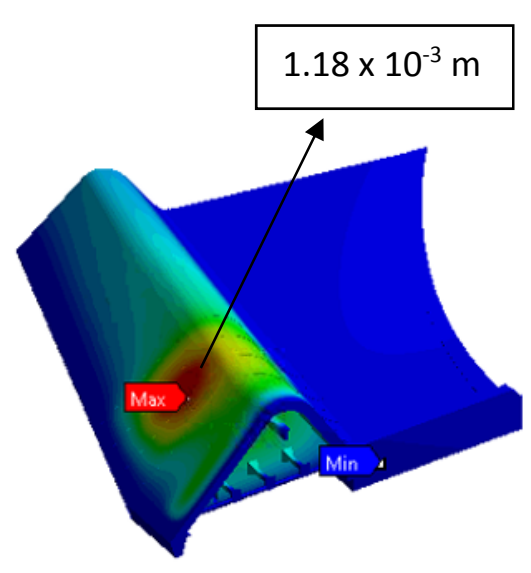

Figure 5: ODS of left bank section
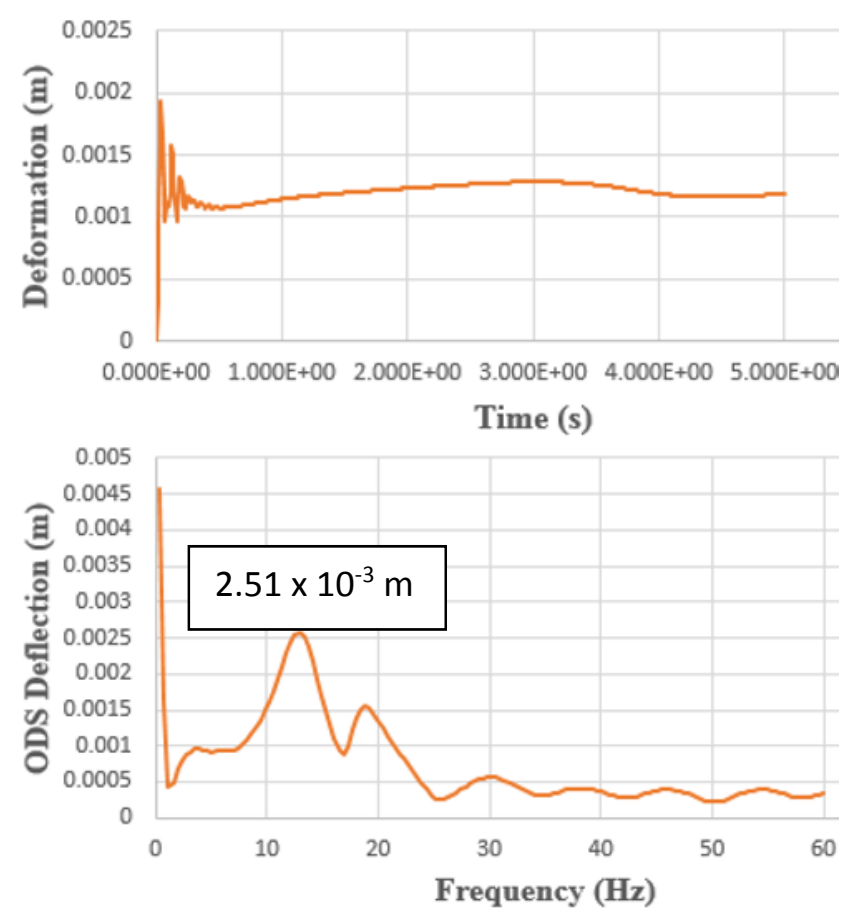

Figure 6: Time domain (above) and frequency domain (below) of deformation at left bank section 


\section{Comparison between ODS and Modal Analysis of the Left Bank Section}

Figure 7 shows the comparison between ODS result from transient analysis and mode shape result from modal analysis. It can be observed that the ODS and the mode shape exhibit almost similar result where deformation occurs at the upper part of left bank section. From Figure 8, the ODS and MA deformation occurred at frequency of $13.3 \mathrm{~Hz}$ and $52.3 \mathrm{~Hz}$, respectively, which means that they are in different frequency range. Due to the fact that these two frequencies do not coincided, there is no significant failure to the left bank section of Chenderoh Dam for the normal water spilling condition.

ODS

Operating frequency $\left(f_{o}\right)=13.3 \mathrm{~Hz}$ Amplitude $\left(x_{0}\right)=2.51 \times 10^{-3} \mathrm{~m}$

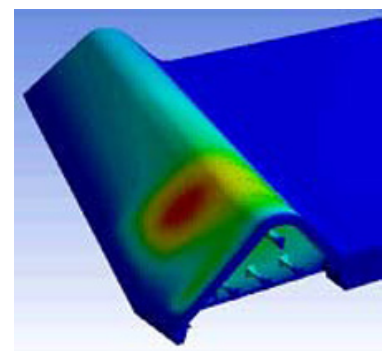

Mode Shape

Natural frequency $\left(f_{n}\right)=52.3 \mathrm{~Hz}$ Amplitude $\left(x_{n}\right)=6.96 \times 10^{-4} \mathrm{~m}$

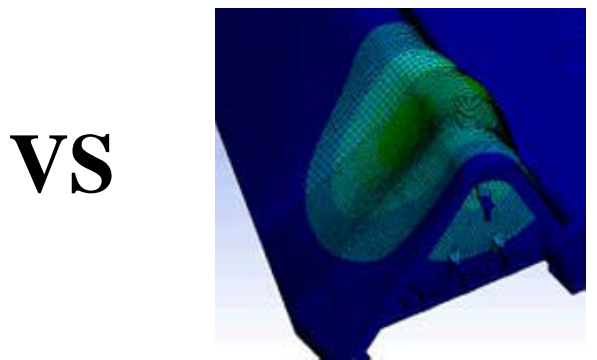

Figure 7: Transient vibration in ODS (left) and bending movement of mode shape in MA (right) of the left bank section

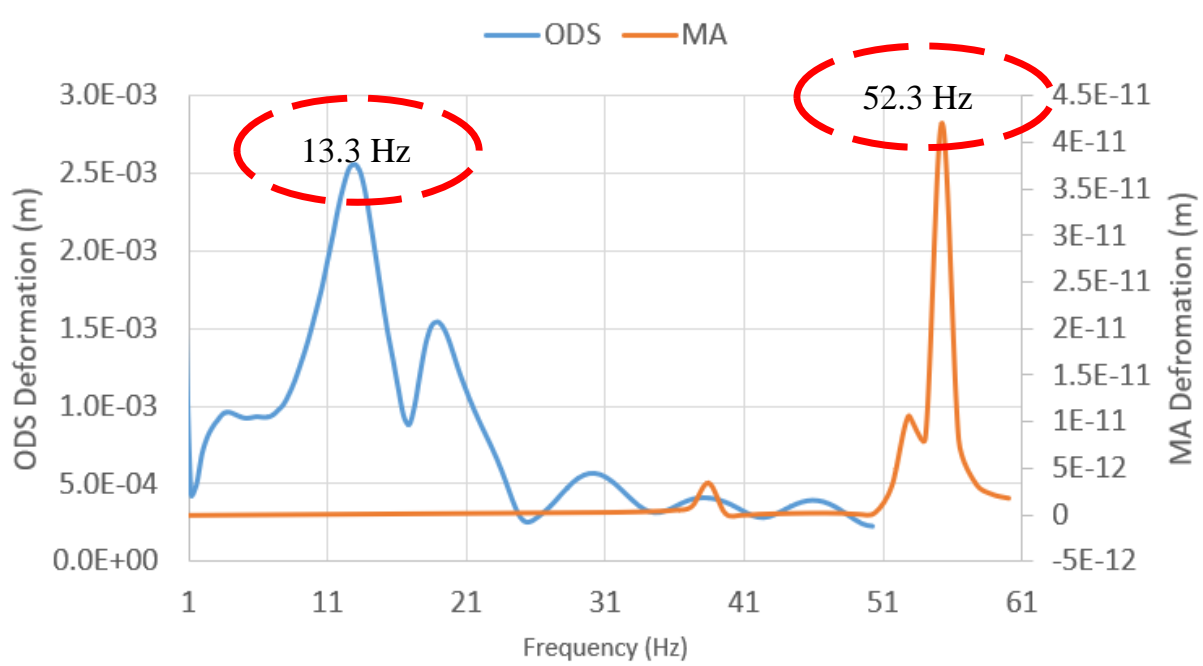

Figure 8: Comparison of MA deformation and ODS deformation in frequency domain

\section{CONCLUSION}

In this study, prediction of the flow-induced vibration response of the Chenderoh Dam left bank section has been successfully carried out. Its can be concluded that: 
1) The modeling of the left bank section of the dam structure has been successfully done in SolidWorks software.

2) The two-way FSI study of the left bank section has been conducted in ANSYS software using transient structural, fluent and system coupling.

3) The ODS result of the left bank section has been achieved in terms of time and frequency domain graphs. The highest overall deflection occurs at operating frequency of $13.3 \mathrm{~Hz}$ with displacement value of $2.51 \times 10^{-3} \mathrm{~m}$.

4) Comparison between ODS and mode shape has been made where both deflection occurred at the upper part of left bank section and no deflection at apron. Since both deflections occurred at different frequencies, there is no critical failure to the left bank section of Chenderoh Dam.

\section{ACKNOWLEDGEMENTS}

The authors would like to acknowledge Universiti Sains Malaysia and Uniten R\&D

Sdn. Bhd. for providing the facilities and financial assistance under accounts (304/PMEKANIK/60313052 and U-841).

\section{REFERENCES}

[1] Virtual Prototypes (Flow-Induced Vibration). Retrieved from: https://www.ansys.com/other/virtual-prototypes/flow-induced-vibration

[2] Fluid-Structure Interaction. Retrieved from: https://www.comsol.com/multiphysics/fluid-structure-interaction

[3] Javanshir I., Javanshir N., Barmaki R. and Mahmoodi M. (2015). Modeling of the Fluid-Induced Vibrations in Sliding Gate Dams. Journal of Vibroengineering, Vol.17, Issue 1, p. 478-486.

[4] Sanchez D. and Salazar J. (2010). On the Effects of Water Discharge Through Radial Gates at the Caruachi Dam. Proceedings of the ASME $201010^{\text {th }}$ Biennial Conference on Engineering Systems and Analysis. 10.1115/ESDA2010-24080. 